\title{
PEMAHAMAN MAHASISWA TERHADAP KONDISI MANAJEMEN PENGETAHUAN DAN MANAJEMEN INOVASI PTS DKI JAKARTA
}

\author{
Dyah Budiastuti \\ Management Department, School of Business Management, BINUS University \\ Jln. K. H. Syahdan No. 9, Palmerah, Jakarta Barat 11480 \\ dyanto23@yahoo.com
}

\begin{abstract}
Private university (PTS) is a business that is based on knowledge; and relies on innovation in efforts to achieve the performance and competitive advantages. As a result, the implementation of knowledge management and innovation management becomes very important. This research aims to determine students' understanding of the condition of knowledge and innovation management and its influence on the achievement of performance in 5 private universities in region III Kopertis Jakarta with the most number of active students. Data were analyzed using descriptive statistics. The results showed that the condition of knowledge management is able to create the value, and the condition of innovation management has enough value-added for stakeholders.
\end{abstract}

Keywords: knowledge management, innovation management

\begin{abstract}
ABSTRAK
Perguruan tinggi swasta (PTS) adalah bisnis yang bertumpu pada pengetahuan, dan mengandalkan inovasi dalam upaya untuk mencapai kinerja dan keunggulan bersaing. Akibatnya implementasi dari manajemen pengetahuan dan manajemen inovasi menjadi sangat penting bagi PTS yang bersangkutan. Penelitian ini bertujuan untuk mengetahui pemahaman mahasiswa terhadap kondisi manajemen pengetahuan dan manajemen inovasi serta pengaruhnya terhadap pencapaian kinerja 5 PTS di Kopertis Wilayah III DKI Jakarta dengan jumlah mahasiswa aktif terbanyak. Data dianalisis dengan menggunakan metode statistik deskriptif. Hasil penelitian menunjukkan bahwa kondisi manajemen pengetahuan mampu menciptakan nilai, dan kondisi manajemen inovasi cukup mampu memberikan nilai tambah bagi stakeholder.
\end{abstract}

Kata kunci: manajemen pengetahuan, manajemen inovasi 


\section{PENDAHULUAN}

Indonesia sebagai kekuatan ekonomi terbesar ke-16 di dunia tergabung dalam G20 kelompok yang menguasai $90 \%$ produk domestik bruto dunia, $80 \%$ perdagangan global, dan 2/3 populasi dunia. Data dari Bank Dunia menunjukkan pertumbuhan ekonomi Indonesia pada 2011 adalah sebesar 6,4\% dan jumlah penduduk yang mencapai lebih dari 242,3 juta jiwa dengan pendapatan domestik bruto mencapai USD846,8 juta. Negara ini tampil sebagai potensi kekuatan ekonomi dan politik yang sangat besar dan berpengaruh di dunia. Namun demikian, menurut Human Development Report yang diterbitkan oleh UNDP pada 2 November 2011, Indonesia memiliki indeks perkembangan manusia yang masih menengah yakni pada peringkat 124 dari 187. Selain itu, pada era pengetahuan saat ini mengandalkan jumlah penduduk yang tinggi dengan tenaga kerja yang murah tidak dapat lagi digunakan sebagai kekuatan untuk meningkatkan daya saing bangsa. Pasar dunia menuntut kualitas sumber daya manusia dengan standar yang senantiasa berubah makin tinggi dan pendidikan menjadi faktor yang sangat signifikan untuk meningkatkan kualitas dan daya saing sumber daya manusia Indonesia.

Era kapitalisme pengetahuan juga menuntut peran manajemen pengetahuan untuk mengubah pengetahuan individual menjadi pengetahuan yang dapat digunakan secara organisasional. Ditambah lagi perguruan tinggi sendiri sebagai suatu knowledge institution terlibat langsung dalam proses kreasi, diseminasi, dan pembelajaran. Di samping itu kemampuan organisasi dalam hal ini memperjelas kembali hubungan antara pendidikan, kinerja, dan pembelajaran organisasional.

Terkait dengan hal tersebut, peran perguruan tinggi sebagai penghasil tenaga kerja yang bermutu (qualified manpower) dan penghasil pengetahuan sangatlah penting agar dapat menjadi kekuatan dalam meningkatkan daya saing bangsa. Dari data akreditasi 5 PTS dengan jumlah mahasiswa aktif terbanyak di Kopertis wilayah III DKI Jakarta, ditemukan masih banyaknya program studi yang tidak terakreditasi A dan dengan nilai akreditasi institusi B. Padahal pencapaian nilai akreditasi ini merupakan indikator dari pencapaian kinerja program studi atau PTS bersangkutan. Hasil penelitian Budiastuti (2013) terhadap pimpinan PTS di DKI Jakarta memperlihatkan bahwa kinerja PTS di DKI Jakarta belum tercapai. Hal ini disebabkan PTS di DKI Jakarta belum mampu mengelola pengetahuan yang muncul sebagai akibat dari kegiatan pembelajaran, penelitian, layanan, pengelolaan organisasi dan sumber daya; dan dalam mengelola inovasi dalam menghasilkan program, produk, dan proses pembelajaran.

Sebagai perguruan tinggi swasta yang dalam pengelolaanya bergantung penuh pada tuition fee mahasiswa, jumlah mahasiswa aktif menjadi kunci keberlanjutan PTS bersangkutan. Akan tetapi, kondisi PTS di DKI Jakarta menunjukkan bahwa rata-rata pertumbuhan jumlah pendaftar per PTS rendah dan rata-rata pertumbuhan jumlah mahasiswa baru per PTS rendah (Kemendikbud, 2006-2011). Belum lagi tantangan untuk mengubah mindset orangtua terhadap kualitas proses pembelajaran, layanan, maupun kualitas lulusan yang dihasilkan perguruan tinggi swasta dianggap lebih rendah dibandingkan perguruan tinggi negeri.

Sebagai PTS yang berada di pusat ibu kota negara, kondisi PTS di DKI Jakarta menjadi barometer keberhasilan pendidikan tinggi di Indonesia. Untuk itu diperlukan berbagai upaya dalam menghadapi tuntutan pengguna yang makin tinggi dan berubah dengan cepat melalui perbaikan proses dan pengelolaan sumber daya yang kreatif dan inovatif. Dan melalui pengelolaan pengetahuan dan inovasi yang efektif diharapkan PTS di DKI Jakarta menjadi unggul dan mampu bersaing di dunia global.

Rumusan masalah penelitian ini adalah tentang kondisi manajemen pengetahuan universitas swasta di DKI Jakarta dan kondisi manajemen inovasi universitas swasta di DKI Jakarta. Sedangkan 
tujuan penelitian adalah mengkaji kondisi manajemen pengatahuan universitas swasta di DKI Jakarta dan mengkaji kondisi manajemen inovasi universitas swasta di DKI Jakarta.

\section{METODE PENELITIAN}

Penelitian ini menggunakan metode survei deskripktif yang bertujuan untuk memperoleh gambaran atau karakteristik tentang kondisi manajemen pengetahuan dan manajemen inovasi dari 5 universitas swasta Kopertis Wilayah III DKI Jakarta. Menurut Evaluasi Program Studi Berbasis Evaluasi Diri/EPSBED (2011), 5 universitas swasta tersebut memiliki mahasiswa terbanyak, yaitu: Universitas Gunadarma, Universitas Bina Nusantara, Universitas Trisakti, Universitas Mercu Buana Jakarta, dan Universitas Katolik Indonesia Atma Jaya. Penelitian dilakukan terhadap 100 mahasiswa dari 5 universitas tersebut; dan data dianalisis dengan metode statistik deskriptif.

Konsep manajemen pengetahuan dalam penelitian ini adalah pendekatan sistematis yang dilakukan perguruan tinggi untuk mengelola informasi dan knowledge yang digunakan untuk menciptakan atau meningkatkan value (nilai) jasa. Dimensi manajemen pengetahuan terdiri dari komponen manajemen pengetahuan, tahapan manajemen pengetahuan, dan lingkup manajemen pengetahuan. Sedangkan yang dimaksud dengan manajemen inovasi merupakan kegiatan inovasi di perguruan tinggi dalam menciptakan produk, program, dan layanan yang memberikan nilai tambah bagi stakeholder perguruan tinggi. Manajemen inovasi mempunyai dimensi kepemimpinan yang inovatif, pengelolaan risiko inovasi, kreativitas dalam organisasi, integrasi organisasi, manajemen proyek inovasi, manajemen informasi, perlindungan karya inovatif, dan pemahaman akan pasar. Kinerja merupakan kondisi/hasil pencapaian perguruan tinggi dalam menjalankan misinya. Kinerja perguruan tinggi mempunyai dimensi efisiensi, efektivitas, produktivitas, kualitas, inovasi, kepuasan, dan ketahanan keuangan/keberlanjutan.

\section{HASIL DAN PEMBAHASAN}

\section{Kondisi Manajemen Pengetahuan}

Saat ini dunia memasuki perekonomian berbasis pengetahuan, yakni ketika bisnis mulai bergeser dari manufaktur ke pelayanan (service economy). Pada era ekonomi berbasis pengetahuan peran elemen produksi seperti lahan, tenaga kerja kasar, dan modal konvensional atau alat produksi sudah mulai mengecil. Tenaga kerja yang dibutuhkan tidak lagi berdasarkan kuantitas namun berdasarkan kualitas. Drucker (1995) berkeyakinan: "Knowledge has become the key economic resource and the dominant and perhaps even the only source of comparative advantage." Sedangkan Housel dan Bell (2005) mengartikan knowledge sebagai: "an ideational (i.e., conceptual rather than physical) construct generated through the agency of the human mind." Metaxiotis dan Psarras (2003) berpendapat "Knowledge belongs to the family of steadily increasing invisible corporate assets that include management system, patents, brand identity and corporate reputation.” Ikuko Tanaka dalam Harvard Business Review on Knowledge Management mengilustrasikan bahwa terdapat dua jenis knowledge yang sangat berbeda sebagai berikut. Pertama, explicit knowledge besifat formal dan sistematik sehingga sangat mudah untuk dikomunikasikan dan dibagikan, seperti dalam bentuk spesifikasi produk atau rumus-rumus atau formula-formula yang ilmiah atau program-program

komputer. Kedua, tacit knowledge bersifat lebih personal yang sangat susah untuk dirumuskan apalagi dibagikan dan berakar pada tindakan dan komitmen individual dalam konteks yang yang spesifik. Tacit knowledge di dalamnya terdapat kemampuan teknikal yang informal yang susah untuk diwariskan yang diistilahkan dengan "know-how". Pada saat yang bersamaan tacit knowledge 
memiliki dimensi kognitif yang sangat penting yang di dalamnya termasuk mental models, keyakinan serta pandangan yang susah untuk diartikulasikan. Sedangkan menurut Debowski (2006) manajemen pengetahuan diartikan sebagai "the process of indentifying, capturing, organizing, and disseminating the intellectual assets that are critical to the organization's long term performance." Lin dan Wei (2004) menyatakan: "Knowledge management is established on the 'enterprise knowledge', which promotes the enterprises to accumulate core competency through extraction and innovation of knowledge, so as to realize the visions and the objectives of the enterprises."

Budiastuti (2013) menjelaskan bahwa knowledge, selain merupakan unsur pembentuk keunggulan bersaing yang berkesinambungan, juga merupakan value yang diciptakan oleh perguruan tinggi untuk disampaikan kepada konsumennya. Sehingga perspektif knowledge pada perguruan tinggi mengandung pengertian penggalian knowledge secara internal dan eksternal, baik sebagai sumber daya maupun sebagai output dari proses pengembangan knowledge management yang dijalankan oleh perguruan tinggi itu sendiri. Oleh karena itu penting bagi perguruan tinggi untuk menyediakan tempat yang dapat menyimpan knowledge yang tercetak maupun yang berbentuk digital. Fasilitas ini tentu saja juga membutuhkan penggunaan teknologi informasi yang unggul dalam mengelolanya. Selanjutnya knowledge haruslah dilihat sebagai aset yang bernilai tinggi bagi organisasi. Nonaka (1998) mengatakan: "In an economy where the only certainty is uncertainty, the one source of lasting competitive advantage is knowledge. And yet, few managers understand the true nature of the knowledge-creating company-let alone how to manage it." Hal ini menunjukkan betapa bernilainya knowledge bagi perusahaan apalagi bagi perguruan tinggi yang merupakan organisasi yang bertumpu pada sumber daya manusia. Perguruan tinggi akan melihat produk bahan ajar yang dikembangkan melalui pemanfaatan knowledge management sebagai aset yang berharga. Memanfaatkan manajemen pengetahuan sebagai dasar untuk pengambilan keputusan akan meningkatkan kualitas keputusan itu sendiri, sehingga perguruan tinggi tidak mengulangi kesalahan yang sama dari masa lalu. Tantangannya adalah bagaimana perguruan tinggi mampu mengembangkan organisasi yang dengan budaya knowledge creation, knowledge sharing, dan knowledge utilization, serta bagaimana membangun suatu sistem kerja yang mampu menggunakan knowledge management untuk menciptakan keunggulan kompetitif, terutama melalui keunggulan program-program pendidikan yang tercermin dalam kurikulum yang menghasilkan lulusan yang berkualitas tinggi dan sesuai dengan kebutuhan industri yang saat ini makin ketat persaingannya dan menuntut banyak keunggulan.

Hasil penelitian menunjukkan bahwa menurut mahasiswa pendekatan sistematik yang dilakukan universitas swasta dalam mengelola informasi dan knowledge yang digunakan untuk menciptakan atau meningkatkan nilai jasanya adalah tinggi. Artinya secara umum mahasiswa merasa bahwa jenis teknologi, tingkat kelengkapan teknologi, tingkat kemudahan penggunaannya, jumlah kegiatan, jumlah yang terlibat, jumlah yang memanfaatkan, dan jumlah tenaga yang mengelola manajemen pengetahuan di universitasnya mampu memberikan manfaat. Selain itu jumlah knowledge yang dikembangkan, dikategorikan, dan diakses mampu memberikan manfaat bagi mahasiswa. Demikian juga halnya dengan jumlah implementasi manajemen pengetahuan di bidang akademik, nonakademik, dan pengembangan organisasi dirasakan mahasiswa mampu memberikan manfaat.

\section{Kondisi Manajemen Inovasi}

Inovasi merupakan keberhasilan ekonomi berkat adanya pengenalan cara baru atau kombinasi baru dari cara-cara lama dalam mentransformasi input menjadi output (teknologi) yang menghasilkan perubahan besar atau drastis dalam perbandingan antara nilai guna yang dipersepsikan oleh konsumen atas manfaat suatu produk (barang dan/atau jasa) dan harga yang ditetapkan oleh produsen (Fontana, 2011). Inovasi akan dikatakan bermanfaat ketika dapat menciptakan nilai lebih bagi semua stakeholder terlebih bagi konsumen, masyarakat, dan lingkungan hidup serta tentu saja bagi organisasi itu sendiri. Luecke (2009) mendefinisikan inovasi sebagai "the embodiment, combination, and/or synthesis of knowledge in original, relevant, valued new products, processes, or services.” Menurut Roger (seperti yang dikutip oleh Dasgupta et al., 2009) inovasi adalah "an idea, practice or an object 
that is perceived as a new way by an individual or other unit of adoption." Sementara itu Drucker (seperti yang dikutip oleh Alstete \& Meyer, 2010) mengatakan bahwa inovasi merupakan "the application of knowledge to produce new knowledge. Luecke juga membedakan inovasi menjadi 2 jenis yang berbeda, yaitu: 1) Incremental innovationis generally understood to exploit existing forms of technologies. It either improves on something that already exist or reconfigures the existing form or technology to serve some others purposes. 2) Radical innovation is something new to the world and a departure from existing technology or methods.

Sedangkan manajemen inovasi menurut Fontana (2011) adalah proses menata kelola inovasi agar menghasilkan kesuksesan secara social dan ekonomi secara efisien dan efektif dan dengan memampukan seluruh sumber daya organisasi, yang sudah ada di dalam organisai atau yang diperoleh secara baru dari luar organisasi, dan yang mengacu pada prinsip-prinsip manajemen inovasi dan prinsip-prinsip inovasi. Terdapat delapan prinsip manajemen inovasi menurut Fontana (2011), yaitu: kepemimpinan yang inovatif, pengelolaan resiko inovasi, kreativitas dalam organisasi, integrasi dalam organisasi, manajemen proyek inovasi, manajemen informasi, perlindungan karya inovasi, pemahaman akan pasar.

Hasil penelitian menunjukkan bahwa menurut mahasiswa kegiatan inovasi yang dilakukan universitas dalam menciptakan produk, program, dan layanan cukup mampu memberikan nilai tambah bagi stakeholder. Ini berarti pimpinan universitas cukup mampu memberikan penjelasan ke mahasiswa tentang visi dan misi universitas. Pimpinan universitas cukup mampu membentuk lingkungan untuk berinovasi, cukup mampu menentukan program/proyek inovasi yang akan dijalankan, cukup mampu mendorong keterlibatan staf dalam berinovasi, cukup mampu memberikan perlindungan akan kemungkinan kegagalan berinovasi, cukup mampu mendorong keberadaan tim untuk berinovasi, mampu memberikan dukungan informasi, imbalan jasa dan pengakuan pada tim inovasi, cukup mampu menyesuaikan program inovasi dengan tujuan jangka panjang organisasi, cukup mampu mengkaitkan antarprogram/proyek inovasi dan mengaitkannya dengan unit organisasi yang ada, dan mengaitkan dengan organisasi eksternal. Hasil penelitian juga menunjukkan bahwa pimpinan universitas cukup mampu membuat perencanaan proyek inovasi, mengatur keterlibatan stakeholder dalam proyek inovasi, mengatur aliran informasi, efisiensi sumber daya untuk berinovasi, menyediakan akses informasi, melindungi karya inovasi, cukup mampu berkomunikasi dengan konsumen, cukup mampu memahami kebutuhan konsumen, dan cukup cepat merespons permintaan konsumen.

\section{SIMPULAN}

Simpulan yang diperoleh dari penelitian adalah sebagai berikut. Pertama, kondisi manajemen pengetahuan yang merupakan pendekatan sistematik yang dilakukan perguruan tinggi untuk mengelola informasi dan knowledge yang digunakan untuk menciptakan atau meningkatkan nilai jasa pada universitas swasta di DKI Jakarta mampu menciptakan nilai bagi universitas yang bersangkutan. Kedua, kondisi manajemen inovasi yang merupakan kegiatan inovasi di perguruan tinggi dalam menciptakan produk, program, dan layanan cukup mampu memberikan nilai tambah bagi stakeholder.

\section{DAFTAR PUSTAKA}

Alstete, J. W. and Meyer, J. P. (2010). Structuring Innovation in Knowledge Management Platform: Perception and Practices. Journal of information and knowledge management. 9(1), 1-14. 
Budiastuti, D. (2013). Membangun Strategi Kerjasama melalui Implementasi Manajemen Pengetahuan dan Manajemen Inovasi untuk Meningkatkan Kinerja Perguruan Tinggi. Disertasi S3. Tidak dipublikasikan. Bandung: Universitas Padjajaran.

Debowski, S. (2006). Knowledge Management. Sydney: John Wiley \& Sons.

Drucker, P. F. (1995). Managing in a Time of Great Change. Oxford: Butterworth Heinemann.

Fontana, A. (2011). Innovate we can! Manajemen Inovasi dan Pencipta Nilai. Edisi Revisi. Jakarta: Cipta Inovasi Sejahtera.

Housell and Bell. (2005). Measuring and Managing Knowledge. Columbus: McGrawHill.

Luecke, R. (2009). The Innovator’s Toolkit. Boston: Harvard Business Press.

Metaxiotis, K. and Psarras, J. (2003). Applying knowledge management in higher education: the creation of learning organization. Journal of information and knowledge management. 2(4), 353-359.

Nonaka, I., et al. (1998). Harvard Business Review on Knowledge Management. Boston: Harvard Business School Press. 